Verhaal en Lezer: Een Onderzoek naar enige Structuuraspecten van 'Van Oude Mensen, de Dingen die Voorbijgaan' van Louis Couperus. Groningen: Tjeenk Willink.

BRONZWAER, W. J.M.

1970 Tense in the Novel: An Investigation of Some Potentialities of Linguistic Criticism. Groningen: Wolters-Noordhoff

1946 "The Historical Present in Narrative Literature, Particularly in Modern German Fiction." The Journal of English and Germanic Philology XLV, pp. 43-67.

HAMBURGER, KÄTE

1957 Die Logik der Dichtung. Stuttgart: Ernst Kleft.

JANSSEN, THEO A. J. M.

1989 "Tempus: Interpretatie en Betekenis." De Nieuwe Taalgids 82, pp.305-329. 1991 "Tenses and Demonstratives: Conspecific Categories." In R. A. Geiger and B. Runzkive Linguistics Research 2). BerlinNew York: Mouton de Gruyter. (in (Cognitiv

PAARDEKOOPER, P. C.

1957 "De 'Tijd' als Spraakkunstgroep in het ABN." De Nieuwe Taalgids 50 , pp.38-45.

RIJPMA, E. and F. G. SCHURINGA

Nederlandse Spraakkunst. Edited by dr. Jan van Bakel, $23^{\text {rd }}$ ed., Groningen: Wolters-Noordhoff.

Works Quoted

COUPERUS, LOUIS

1906 Van Oude Menschen, de Dingen, die Voorbijgaan. Amsterdam: Veen. Old People and the Things that Pass. tr. Alexander Teixeira de Mattos. Leyden/London: Sythoff/Heinemann, 1963.

WILLEM ELSSCHOT

1933 Kaas. Antwerpen: Ontwikkeling, 1955.

ARTHUR VAN SCHENDEL

1930 Het Fregatschip Johanna Maria. Amsterdam: Meulenhoff.
Leonie Cornips

\section{Possessive Object Constructions in Heerlens}

1. Introduction*

In this paper I will discuss some characteristics of the possessive object construction in spoken regional Dutch in Heerlen (henceforth: 'Heerlens'). Heerlen is a town in Limburg, a province in the Southeast of the Netherlands.

Contrary to Standard Dutch (henceforth: $A B N$ ), in Heerlens double objects can appear in a wide range of constructions. Some of them will be

illustrated in section 2. The construction that will be the main topic of this paper is the possessive object construction, in which the indirect object is construed as the possessor of the other object. This construction will be briefly compared with the benefactive construction. In section 3 , it will be shown that both construction types in Heerlens are in various. respects similar to the possessive object and benefactive constructions in French and German. In section 4, however, I will discuss an unexpected and French/German. It will be shown that this difference can be better understood by takins a regional construction type into consideration.

2. Variety of indirect object constructions in Heerlens

One of the characteristics of Heerlens is that it does not only make a productive but also an extensive use of indirect objects in a wide variet of constructions that are unacceptable in ABN. Compare the following examples.
$\begin{array}{rlll}\text { (1) } \mathrm{H} & \text { Ik was } & j e & \text { de wagen } \\ \mathrm{H} / \mathrm{ABN} & \mathrm{Ik} \text { was } & \text { de wagen voor je }\end{array}$
I wash you (i.o) the car
I wash the car for you
(2) H Ik hoef het $\mathrm{He}$ niet te geloven
H/ABN Ik hoef het niet van je te geloven I need it you (i.o) not to believe need it not of you to believe
(3) H
his leg
I do not need to believe
Ik breek hem het been
(ABN: zijn been)
'I am breaking his leg'
(4) $\mathrm{H}$
$\begin{array}{llll}\text { De poes springt je } & \text { op schoot (ABN: op je schoot } \\ \text { the cat jumps you (i.o) onto lap } & \text { onto your lap }\end{array}$ 'The cat jumps onto your lap' In (1) the indirect object is a benefactive and in (2) it is some kind of
'source'. In (3), the indirect object functions as a 'possessive' object. The same is true for the object in (4), but we will see in the next section that it is not a priori clear whether it is a direct or an indirect object. Leaving idiomatic expressions beside, the indirect objects in $(1-4)$ are not possible in ABN. In $(1-2)$, the indirect object NP must be substituted for
by a PP. This option is possible in Heerlens as well. In (3), only a 
genitive specifier can be used. This option is also possible in Heerlens, but gives rise to a marginal result if the possessed object refers to a body-part. In as far as the construction in (4) is possible in ABN, the
prepositional object requires a genitive specifier of its own in addition to the possessive object. This paper mainly deals with the possessive object constructions in (3) and
(4), although some attention will be paid to the benefactive construction
in (1), since this will enable us to highlight some remarkable features of the possessive object construction.

3.1. Benefactives and possessive objects in Heerlens

Consider the following examples of the benefactive construction in Heerlens:

$$
\begin{aligned}
& \begin{array}{l}
\text { (5) H Ik sla je (i.o) a vlieg dood } \\
\text { I beat you }
\end{array} \\
& \text { (6) H Ik ruim hem } \\
& \text { (7) I clean him (i.o) the room PART } \\
& \begin{array}{l}
\text { Ik smeer has (i.o) de boterhammen } \\
\text { I butter her (i.o sandwiches }
\end{array}
\end{aligned}
$$

In all the above examples the indirect object can be replaced by a voor-PP (cf. (1)). The double object construction however seems to imply some 'involvement' of the person referred to by the indirect object in the event described (Van Bree 1981:168). Note that in Heerlens the benefactive is no restricted to contexts in which a transfer of possession is implied as

the case in English (cf. Pijnenburg 1991 and references cited there). The benefactive and possessive object constructions differ with respect to the restrictions placed on the direct or the prepositional object. definite NP, whereas an indefinite NP leads to unacceptability in the possessive object construction. This can be seen in $(8)$ and $(9 a):(9 a)$ is 'the rabbit is eating a carpet for him' (cf. Guéron 1988 for a possible account of this restriction in the possessive object construction).

$$
\begin{array}{ll}
\text { (8) } \mathrm{H} & \text { Ik smeer haar een boterham } \\
\text { I butter her (i.o) a sandwich } \\
\text { (9)a.H } \\
\text { *Het konijn eet hem een tapijt op } \\
\text { the rabbit eats him (i.o) a carpet up } \\
\text { 'The rabbit is eating his carpet' }
\end{array}
$$

Sometimes the use of a definite object leads to ambiguity between a benefactive and possessive interpretation, e.g. (9b) can be either construed as 'the rabbit is eating the carpet for hin' or as 'the rabbit context.

(9)b.H Het konijn eet hem het tapijt op the rabbit eats him (i.o) the carpet up

However, if the direct object refers to a body-part (or something that is intimately related to the indirect object), this ambiguity does no longer show up (cf. (10)). As we will see, Heerlens is similar in this respect to French and German.

(10) H

$$
\begin{array}{ll}
\text { Ik breek hem } & \text { het been } \\
\text { I break him(i.o) the leg } \\
\text { 'I am breaking his leg' }
\end{array}
$$

Before we will go and look at French and German, I want to note that in Heerlens, there are two passive constructions that correspond to the prepositional inalienable possession construction. In (11b) we find the normal (personal) passive counterpart of (1a), whereas we find an mpersonal passiv

(11)a.H Ik tik hem op de vingers

'I hit him on the fingers

b.H Hij wordt op de vingers getik

he is on the fingers hit

H Hem wordt op de vingers getik

Since the possessive object in (11a) can appear in the passive voice eithe as a nominative NP (11b) or as an objective NP (11c), we may conclude that the possessive object hem in (11a) can be either a direct or an indirect object. That the possessive object can be an indirect object can also be seen from the fact that (11a) allons the so-called prive passive as in (12); in the krijgen-passive

(12) H Hi,j kreeg op de vingers getikt
he got on the fingers hit

The sentences in (11b) and (11c) differ in meaning; whereas (11b) is preferably construed as 'he has been hit on the fingers', (11c) can only be metaphorically construed as 'he has been given a reprimand. As expected, the example in (12) can only have the latter meaning as well. As we will see, Heerlens is similar to French and German in this respect.

3.2. Benefactives and possessive objects in French and German

The French and German benefactive and possessive object constructions are similar to the constructions in Heerlens. First, I will give a short characterization of the French constructions. As in Heerlens, there are no (13): (13)F Pierre lui
Pierre him (i.o) has washed ta voiture

But since French has the possessive object construction as well, (13) can like Heerlens be construed either as a benefactive construction, i.e. as 'Pierre washed the car for him' or as a possessive construction, i.e. as the inalienable possession reading is available Note that os in Heerlens the possessed NP

(14)F Je lui ai lavé les mains I $\operatorname{him}(i, 0)$ has washed the hands

In the prepositional construction the possess
s a dative or as an accusative NP (cf. (15)).

(15)a.F Je lui ai frappé sur le nez I him (dat.) have hit on the nose b.F. Je $l^{\prime}$ ai frappé sur le nez 'I him (acc.) have hit on the nose 
An II Hwallons, the difference correlates with a difference in meaning. As (ind ist meen f'roin the glosses, (15a) has a more metaphorical meaning, $A m$ in French and Heerlens, there is no semantic restriction on the German benefactive double object construction. (16)G Er trägt ihm den Koffer zum Bahnhof
he carries him(i.o) the suitcase to the station

The possessive object construction expands to all (abstract) objects having an intimate relationship with the indirect object. As in Heerlens and

(17)G Man ist uns ins Haus eingebrochen

(18)G Er verdirbt ihm he spoils him(i.o) the temper

In the prepositional inalienable possession construction, the possessive NP may have either the dative (19a) or the accusative (19b). As in French and Heerlens, the a-sentence has a metaphorical meaning, whereas the b-sentence

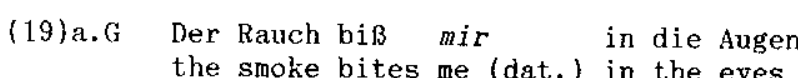
the smoke bites me (dat.) in the eyes

b.G Der Hund hat mich in das Bein gebissen the dog has me (acc.) in the leg bitten

3.3. Conclusion

In the first part of this paper I have presented an overview of several constructions in Heerlens that are only marginal possible or do not occur in $A B N$ (section 2).

In section 3, I have shown that the distribution and the behaviour of the benefactive and the possessive object in Heerlens is the same as in French and German. A possessive object is only grammatical if the possessed object is definite. In the double object construction, a possessive interpretation is favoured if there is some kind of intimate relation between the possessor and the possessed object (especially if the latter refers to a body part). In the prepositional construction, the possessor may be either a direct or an indirect object. If the possessor is a direct object, the construction has a literal meaning, whereas only a metaphorical meaning is
possible if the possessor is an indirect object.
4. The reflexive inalienable possession construction

We have seen that Heerlens is similar to French and German in various respects. In this section, however, I will discuss a difference between Heerlens and French/German with respect to the reflexive possessive objec construction, i.e. the construction in which the possessive object is a reflexive. It will be shown that this difference can be understood by

4.1 An unexpected difference between French/German and Heerlens

In French and German; there is an alternation of a reflexive possessive object and a genitive specifier. In $(20 / 21 \mathrm{a})$, for instance, se/sich can be

(20)a.F Il se coupe le doigt

b.F he refl, cuts the finger

b.F coupe son doigt

(21)a.G Er bricht sich das Bein

he breaks refl. the leg

Er bricht sein Bein
he breaks his leg

The a-sentences with a reflexive clitic or NP are common constructions in French and German. In both languages the reflexive construction expresses coincidental event; it is by accident that someone cuts his own finger (20a) or breaks his own leg (21a). The b-sentences with a genitive specifier however are rare and change coincidence into action; the event is deliberately performed. Besides, the possessed object is preferably construed as alienable, i.e. if in these examples the genitive specifier is construed as coreferential with the subject, the object refers to a

As can be seen in (22), in Heerlens similar reflexive possessive constructions can be found as in French and German.

(22) H Hij breekt zich het been
he breaks refl. the leg

It is very remarkable, though, that the interpretation of (22) differs from the a-examples in (20) and (21). Whereas the French and German examples refer to a coincidental eyent, $(22)$ can only refer to a deliberate action. object has been dropped. Contrary to French and German, the inalienable possession reading will be maintained, i.e. the subject of $(23)$ is construed as the possessor of the object. In accordance with this, the possessed object will appear with a definite article. This can be seen in

(23)H Hij breekt het been

'He breaks his own leg'

In Heerlens, the construction with a genitive specifier is marginally possible. Probably, this construction must be viewed as a borrowing from
ABN. For reasons of space, I will not discuss this matter here.

The difference between French and German on the one hand and Heerlens on the other can be summarized as follows. In French and German the reflexive in Heerlens this construction con only be tons a conct, whereas 
If the reflexive object is not present, the situation is reversed. Further, in French and German the replacement of the possessive object by a genitive specifier results in the loss of the inalienable possession reading. In available after dropping the possessive object, since the subject may act as a possessor.

4.2 The band lek-construction in Heerlens

How can the dissimilarities discussed in 4.1 be better understood? I will argue that the different semantic features of the construction in Heerlens is connected with the so-called band lek-construction (cf. Van Bree 1981). Consider the following examples:

(24) H Hij heeft de band lek

he has the tyre punctured

'He has a flat tyre'

(25) H Hi,j heeft de ogen rood

he has the eyes red

'He has red eyes'

In these examples the subject is interpreted as the possessor of the object which must be definite as in the possessive object construction (cf. Van Bree 1981:128). In (24-25) a state is described (24), for example, refer to a state of 'a tyre being flat'. In ABN this state cannot be expressed by the same means, but has to be described with the help of a copular construction as in (26) or with the help of an attributive adjective as in

(26) ABN 2i.jn band is lek

(27)ABN Ik heb een lekke ban I have a flat tyre

Given the ungrammaticality of (28), we may conclude that as in ABN the band lek-construction is not possible in Standard German (although according to Van Bree 1981, it may be present in some western dialects). In French however, the band lek-construction is known as well (cf. Van Bree 1.981). This can be seen in (29).

(28)G *Er hat die Haare schön he has the hair beautiful 'His hair is beautiful

(29) F Il a le pantelon blanc he has the trousers white 'Hi.s trousers are white'

I will come back to this later and return to Heerlens now. As can be seen in (30), the band lek-construction can be formed with the verb krijgen

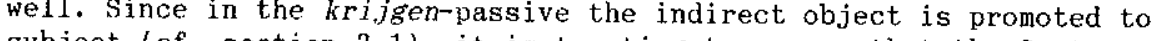
subject (cf. section 3.1), it is tempting to assume that the S-structure subject of the band lek-construction is an underlying indirect object as
(30) H Hij kreeg de band lek

nctured 'His tyre is flat' The assumption that the subject in (24-25) is an underlying indirect object may appear with an overt possessive object. This can be seen in (31).

(31) $\mathrm{H} \mathrm{Hem} \mathrm{is} \mathrm{de} \mathrm{band} \mathrm{lek}$ him is the tyre punctured

Further, it explains that the subject behaves as a possessive subject in (24-25) and that a possessive object cannot be added to this construction

(32).H *Hij heeft zich de band lek In $(24-25)$ a predicative adjective has been used. If we use a participle as
in (33), we would expect an ambiguity to appear, since the participle can be constived either as an adjective or as a past participle. Consequently, state. This expectation is not confirmed; the examples can only be construed as states.

(33) H Jan heeft de jas gescheurd
Jan has the coat torn

We may conclude from this that for some strange reason the participle can the construed as an adjective in (33), ile. re are dealing here with can only be interpreted as the possessor of the object.

The assumption that the participle can be an adjective can be tested, since in embedded clauses a past participle can either follow or precede the cinite volowing adjectici

(34) a.H dat Jan het been heeft gebroken

that Jan the leg has broken H dat Jan het been gebroken heef
that Jan the leg broken has

Only (34b) is construed as a band lek-construction. Note, however, that in Heerlens the order of the verbal sequence in (34a) is only marginally possible.

Summarizing, we may conclude the participle can only be interpreted as a past participle if the subject of the sentence does not behave as a possessor. If, on the other hand, the subject is a possessor, the participle has to be interpreted as an adjective, i.e. the construction is construed as a band lek-construction. This may be accounted for if we assume that in Heerlens a possessor has to be an underlying indirect

4.3 Reflexive possessive object construction reconsidered

Let us now consider the examples in (22) and (23), repeated here for convenience as $(35)$ and $(36)$.

(35) H Hij breekt zich het been he breaks refl. the leg

(36) H Hij breekt het bee 


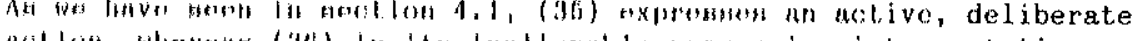

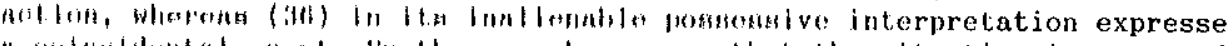

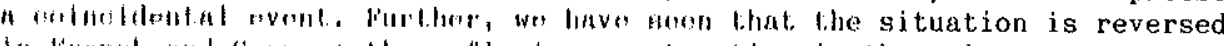

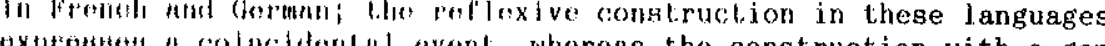

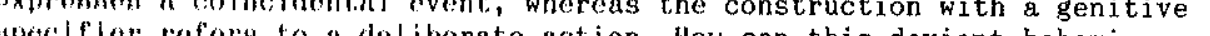
Heen leas be understood? Both (35) and (36) are verbal sequences. The fact that (35) can only refer to a deliberately performed action is only due to the presence of the reflexive object. I think we can understand this interpretation of (35) better if we take the perfect tense counterparts

(37) H Hij heeft zich het been gebroken

(38) H he has refl. the leg broken

$$
\begin{aligned}
& \text { Hij heeft het been gebroken } \\
& \text { he has the leg broken }
\end{aligned}
$$

Let us first consider (38). This example has all the features of the band lek-construction discussed in the previous subsection: (i) the object is a definite NP, and (ii) the subject is interpreted as the possessor of the object. Since (38) can only be understood as referring to a state, we must conclude that (38) is construed as a band lek-construction.

Example (37) shows that in addition to the manipulation of the order of the verbal sequence (cf. (34)), participle constructions can be disambiguated by insertion of the reflexive object zich. If we add this reflexive, as in (37), the example can only be construed as a verbal construction. This is not surprising, since we have seen that a reflexive possessive object
cannot appear in the adjectival band lek-construction (cf. (32)).

Note that in Heerlens the reflexive zich is more than just a possessive object, since it does not only make the sequence verbal, but also prevents the subject must be an agent. This explains why (35) can only be construed as an action.

Since (37) has an active reading, the same must be true for (35). Consequently, zich must be construed as an argument in the same way as hem
in (39).

(39) H Ik breek hem het been I break him the les

Because (37) is treated on a par with (39), this example must also refer to a deliberate action. The argument-status of the reflexive object explains why (37) cannot be interpreted as a colncidental event as the reflexive possessive construction in French and German can.

Summarizing, we may conclude that, despite appearance, the constructions I have discussed in this subsection are not similar to French and German examples in (20) and (21).
5. Conclusion

In this paper I have discussed the possessive object construction in Heerlens. In section 3, it has been shown that the distribution of this construction is quite similar to the one in French and German. In section 4 , we encountered an unexpected semantic difference between Heerlens on the one hand and rench and German on the other with respect to the reflexive

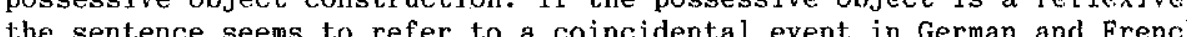
but not in Heerlens. If the reflexive possessive object is absent, the situation is reversed. I have shown that the similarities of these constructions are only apparent. The constructions in Heerlens differ in two respect.s.

First, in Heerlens the subject may act as the possessor of an object that refers to a body-part if there is no possessive object present (cf. (36)). In French and German this is not an available option; the possessor can only appear as a (reflexive) object. Further, the use of a genitive specifier will result in a loss of the inalienable possession interpretation.

Second, in Heerlens the so-called band lek-construction is fully productive. The reflexive zich can be used to distinguish between the band lekreflexive object, the subject of the sentence can no longer act as a possessor. As a result, an active reading arises. Since German does not have the band lek-construction (cf. the ungrammaticality of the German example in (28)), and, consequently, the problems that occur in Heerlens do not occur in German. As we have seen, however, French has the band lekconstruction. The crucial point for French, however, is that the past participle will always appear in front of the direct object (cf $(40)$ ),

(40) F Il a cassé sa jambe he has broken his leg 'He has broken his leg'

(41)F Il a sa jambe cassée he has his leg broken

Consequently, a participle can never be understood as an adjective.

Notes

* I would like to thank Hans Broekhuis for the fruitful discussions that have led to this article. Further, I like to thank Ton Duinhoven, Aafke Hulk, Pieter Muysken, Jan Stroop and an anonymous LIN-reviewer for their comments on an earlier version of this article.

1. The data are taken from Van Bree 1981 (Eastern Dutch), Duden 1984 (German), Gueron 1988 (French) and Pijnenburg 1991 (French and German). The data from Heerlens are collected by myself. Note that I make a distinction between Standard Dutch (ABN), regional Standard Dutch (Heerlens) and the local dialect. Regional Standard Dutch is the variety that is regarded as $A B N$ by the local population. the local dialect that cannot be found in $A B N$; some of thesens discussed in this paper. 
". There are some ABN examples of the meponltional possessive object comstruction that do not contain A pomblive specifier. Although the Hhetuation is not perfectly clear. Hhan exnmples seem to have a specifier of its own, the litum be favoured.

(i)a.ABN Ik tik hem op de vingern 'I hit him on the P'lngers' or 'I give him a reprimand'

b. ABN Ik tik hem op $g i, j n$ vingers 'I hit. hlil on the fingers'

3. Note that most, apeakers of Standard Dutch reject both the impersona passive in (11c) and the krijgen-passive in (12).

4. Of course, this is only the case if the direct object does not have a genitive specifier as in (i).

(i) F Je lui ai lavé le visage de son bébé I him have washed the face of his baby

As will be clear from the gloss, the clitic in (i) can only be construed as a benefactive.

References

Bree, C. van
1981 Hebben-constructies en datiefconstructies binnen het Nederlandse talgebied: een taalgeografisch onderzoek. diss. Leiden.

Duden Grammatik der deutschen Gegenwartssprache. Bibliographisches
Institut: Mannheim, Wien, Zürich.

Guéron, J.

1988 Inalienable possession, Pro-inclusion and lexical chains, in J. Guéron, H.G. Obenauer, J.-Y. Pollock (eds). Grammatical Representa-

Pijnenburg, $\mathrm{H}$.

1991 Datives in French. Amsterdam Studies in Generative Grammar 3, diss. Amsterdam.
Marcel den Dikken

Serial Verbs, 'Object Sharing', and the Analysis of Dative Shift

\section{Introduction*}

From the Caribbean via West Africa to the Far East, we find languages, creoles and pidgins featuring the so-called serial verb construction (SVC for short), illustrated by the example in (1), from Yorùbá, a Kwa language spoken in southwestern Nigeria:

(1) Bợlá sè eeran tà

'Bola cooked some meat and (then) sold it'

(Yorùbá)

Serial verb constructions pose a variety of analytical questions, one of them being the fact, noted by Stewart (1963:145), that 'if two or more successive underlying sentences have the same direct object, this direct object is deleted in each of the sentences other than the first in which it occurs. Baker's (1989) recent study of serialisation is specifically aimed at ceaturing a VP whose multiple heads each assign a $\otimes$-role to the 'shared for a structure (1989) approach to verb serialisation will be briefly reviewed in section 1 . Focusing on the properties of triadic serial verb constructions, I shall subsequently show in section on the a thematic account of 'object sharing' is incorrect. Instead, the word-order restrictions on triadic SVCs and the related V-V compounds of Igbo will be argued to fall out from a specific analysis of triadic constructions, generalising across serialising and non-serialising languages, according to which Dative Shift is a syntactic transformation deriving the double object construction from the dative construction. Spelling out this approach to Dative Shift will be the topic of section 3 . A survey of our major findings in section 4 closes the paper.

\section{A Thematic Approach to 'Object Sharing'}

In his account of serialisation, Baker (1989) argues that obligatory object sharing is a the type in (1) the structural representation in (2), according to which the 'sh a SVC of is an immediate constituent of a one-bar level projection of both the first verb object' second verb. In conjunction with his formulation of the Projection Principle (reproduced here in (3)), the structure in (2) ensures that NP2, the 'shared object', must receive a $\Theta$-role from both V1 and V2, given that NP2 is an immediate constituent of the first-bar projections of both verbs, and on the assumption, incorporated in (3a), that a $\Theta$-marker must assign a role to an immediate constituent of its first-bar projection.

(2)

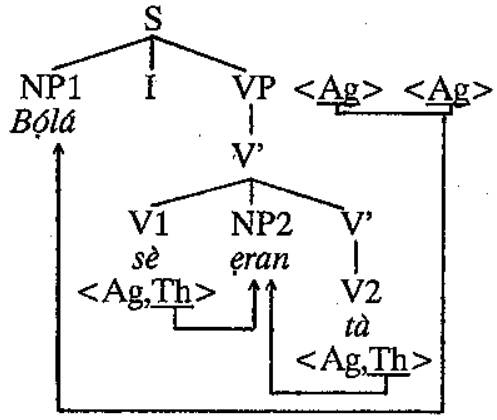

